\title{
Clinical Significance of Periodontitis in Rheumatoid Arthritis Patients: Association with Disease Activity and Functional Status
}

\section{Hanan M Fathi ${ }^{{ }^{*}}$, Nermeen Khairy ${ }^{2}$, Tamer A Gheita ${ }^{2}$, Weam A El Battawy ${ }^{3}$ and Radwa Taha ${ }^{4}$}

${ }^{1}$ Rheumatology Department, Faculty of Medicine, Fayoum University, Egypt

${ }^{2}$ Rheumatology Department, Faculty of Medicine, Cairo University, Egypt

${ }^{3}$ Oral Medicine and Periodontology, Faculty of Oral and Dental Medicine, Cairo University, Egypt

${ }^{4}$ Clinical Pathology Department, Faculty of Medicine, Cairo University, Egypt

*Corresponding author: Hanan M Fathi, Rheumatology Department, Faculty of Medicine, Fayoum University, Egypt, Tel: +201222341906; E-mail: h.fathi@yahoo.com

Received date: February 09, 2018; Accepted date: February 28, 2018; Published date: March 12, 2018

Copyright: (c) 2018 Fathi HM, et al. This is an open-access article distributed under the terms of the Creative Commons Attribution License, which permits unrestricted use, distribution, and reproduction in any medium, provided the original author and source are credited.

\begin{abstract}
Objectives: To evaluate frequency of periodontitis (PD) in rheumatoid arthritis (RA) patients and relate it with clinical characteristics, disease activity, functional status, anti-cyclic citrullinated peptide (anti-CCP) and radiographic scores.

Methods: The study included 60 RA patients and 30 controls. Clinical Disease activity index (CDAI), Modified Health Assessment Questionnaire (MHAQ), visual analogue scale of pain and Scott's modification to Larsen scoring method were assessed. Rheumatoid factor (RF) positivity and anti-CCP titer were measured. Periodontal examination was performed and relevant indices calculated.

Results: The mean age of the patients was $49.1 \pm 13$ years and they were 52 females and 8 males. PD was present in $71.7 \%$ of RA patients versus $46.7 \%$ in control $(p=0.02)$. PD was predominantly generalized $(p=0.004)$ with moderate-severe degree $(p=0.01)$. Age $(p=0.007)$, disease duration $(p<0.0001)$, morning stiffness $(p=0.01)$, CDAl $(p<0.0001)$, MHAQ $(p=0.02)$, CRP $(p=0.02)$, anti-CCP titer $(p=0.01)$ and methotrexate treatment $(p=0.005)$ were significantly higher in RA-PD versus RA. However, gender, smoking, oral hygiene, erythrocyte sedimentation rate, $\mathrm{RF}$, anti-CCP positivity and radiographic scoring were insignificantly different. PD positivity was $96.3 \%$, predominant generalized in $92.6 \%$, moderate $(40.7 \%)$ and severe degree $(37 \%)$ in early RA versus $(51.5 \%, 24.2 \%, 24.2 \%, 12.1 \%$ respectively) in late RA patients. All PD indices were higher in early patients $(p \leq 0.05)$ while teeth loss ( $p=0.03)$ was higher in late cases. CDAI, VAS and ACPA titer all significantly correlated with PD indices $(p<0.05)$.
\end{abstract}

Conclusion: Periodontitis is frequent in RA patients' especially in early cases and is remarkably associated to disease activity and reduced functional status.

Keywords: Rheumatoid arthritis; Periodontitis; ACPA; RF

\section{Key Messages}

Disease activity and functional status in RA especially early cases influenced with periodontal status.

Routine periodontal examination is important to minimize the frequency and severity of periodontitis in RA.

\section{Introduction}

Rheumatoid Arthritis (RA) is a chronic inflammatory autoimmune disease characterized by persistent synovitis, systemic inflammation, production of autoantibodies, and bone destruction preferentially involving the peripheral joints [1]. A remarkable increase in the prevalence of moderate to severe periodontitis (PD) in RA patients has been mentioned [2].

The prevalence of Tempromandibular disease (TMD) in RA patients resulted in extremely varied values $5-86 \%$ [3]. Other secondary orofacial signs/symptoms include: mouth burning, hypo-salivation, xerostomia, salivary gland diseases, gingivitis and periodontitis. PD is a chronic infectious disease caused by Gram-negative anaerobic bacteria, affecting the tissues of protection and support of the tooth, such as gums, periodontal ligament, cementum and alveolar bone [4].

The importance of peptide citrullinationas an etio-pathological event in RA with development of Anti-Citrulinatted Peptide (antiCCP) antibodies [5], and the discovery of a major bacterial species involved in the development and propagation of periodontal disease having a peptide arginine deaminase (PAD) capability of citrullination $[6,7]$ have spotted the light on the possible relation between RA and PD. Both RA and PD present an imbalance between pro-inflammatory and anti-inflammatory cytokines, which is thought to be responsible for the tissue damage resulting in bone destruction [2]. Both RA and PD share a number of pathobiologic processes as similar cellular participation at the inflammatory focus, microenvironmental, serum cytokines, matrix metallo-proteinase and osteoclast-mediated bone destruction [8], common genetic risk factors including the Human Leukocyte Antigen (HLA)-DR shared epitope, polymorphisms and epigenetic modifications in cytokine genes [9] and common interleukin-6 promoter DNA methylation site [10]. 
Histopathologically, sharing intense neutrophilic and mixed cellular infiltrate mostly lymphocytic infiltration [11].

An interrelationship between Rheumatoid Arthritis (RA) and periodontitis has been suggested due to their common pathogenic mechanisms. Protein carbamylationand Neutrophil Extracellular Traps (NETs) formations have been shown to be related to autoimmune conditions, including RA, and were association between with periodontitis severity which is influenced with periodontal treatment [12]. Recently it has been found that the appearance of antiCarbamylated Protein (CarP) antibodies in the sera precedes the onset of RA [13]. Moreover, the presence of CarP was also demonstrated in inflamed periodontal tissue from patients with mild to moderate periodontitis, suggesting that protein carbamylation in RA patients may also be shared by periodontitis [14].

Therefore, we aimed in the current study to assess frequency of periodontitis in Egyptian RA patients and to find a possible association of periodontal indices and severity with disease activity, functional status, anti-CCP, rheumatoid factor (RF) serology and radiographic score.

\section{Patients and Methods}

Sixty patients fulfilling the 2010 American College of Rheumatology/European League against Rheumatism (ACR/EULAR) classification criteria for RA were recruited for the study. They were further classified according to disease duration into early $\leq 3$ years and late $>3$ years from Rheumatology Outpatient Clinics - Faculty of Medicine-Cairo and Fayoum Universities, in collaboration with Oral Medicine and Periodotology Department- Faculty of Dentistry- Outpatient Clinics-Cairo University between January and September 2017. Exclusion criteria were any patients with diabetes mellitus or hepatitis $\mathrm{C}$ or any other autoimmune diseases. The study was approved by the Ethics Committee of Faculty of Medicine, Cairo and Fayoum Universities Hospitals. All patients gave their informed consent to participate in the study. Thirty age and sex matched apparently healthy were taken as control. Patients were thoroughly examined. Pain was evaluated by Visual Analogue Scale (VAS) [15]. The disease activity in RA patients was assessed using the Clinical Disease Activity Index (CDAI) [16]. The functional status was assessed according to the Modified Health Assessment Questionnaire (MHAQ) [17] and Plain Xrays (postero-anterior view) on the hands were obtained for all patients using Scott's modification to Larsen scoring method, 1995 [18].

Diagnosis of PD was according to Armitage, Van der Velden and Lopez et al. [19-21] classification system with increased alveolar bone and periodontal attachment loss. Oral examination included estimation of the Plaque Index (PI), Gingival Index (GI), Probing Pocket Depth (PPD) and Clinical Attachment Loss (CAL). The PI 20 was scored as 0 (gingival area of the tooth free from plaque); 1 (no plaque observed by the naked eye, but plaque is made visible on the tip of a probe after it has been moved over a tooth surface at the entrance of the gingival crevice); 2 (gingival area covered by a thin to moderately thick layer of plaque visible to the naked eye) and 3 (heavy accumulation of soft matter, the thickness of which fills the crevice produced by the gingival margin and the tooth surface.

The GI [21] was scored as 0 (entire absence of visual signs of inflammation in the gingival unit); 1 (slight change in color and texture); 2 (visual inflammation and bleeding tendency from the gingival margin after a periodontal probe is briefly run at the bottom of the gingival crevice and 3 (overt inflammation with tendency to spontaneous bleeding).

The PPD [22] was measured from the free-gingival margin to the base of the periodontal pocket and the CAL measured from the cemento-enamel junction of the tooth to the base of the periodontal pocket [23]. The severity of chronic periodontitis was classified into localized $(<30 \%)$ and generalized ( $>30 \%$ of sites are affected). Furthermore, severity of chronic periodontitis at the site level was classified based on the degree of clinical attachment loss in to: mild $(\mathrm{CAL}=1-2 \mathrm{~mm})$, moderate $(\mathrm{CAL}=3-4 \mathrm{~mm})$ and severe $(\mathrm{CAL} \geq 5 \mathrm{~mm})$ $[24,25]$.

Blood specimens were collected after an overnight fasting analyzed for complete blood count (CBC), erythrocyte sedimentation rate (ESR) by the Westergren method, C-Reactive protein (CRP) calibrated by nephelometry method and rheumatoid factor (RF) assayed with a quantitative immunonephelometry test (Behring, Marburg, Germany).

RF was considered positive when the concentration was higher than the cut-off value of the kit $(15 \mathrm{IU} / \mathrm{ml})$. The liver and kidney function tests were also considered. The quantitative detection of anti-cyclic citrullinated peptide (anti-CCP3) IgG in serum level was performed using a commercially available enzyme linked immunosorbent assay (ELISA) kit provided by INOVA Diagnostics, Inc. USA following the manufacture recommendations.

The statistical program SPSS version 15 was used for statistical analysis. Results were expressed as mean ( \pm standard deviation), or number (percentage). Student's t-test was used to compare continuous variables between patients and controls, and between subgroups of RA patients (RF positive and negative).

The chi-square test for the categorical variables was performed when appropriate. The correlations between variables were presented as the Spearman's correlation coefficient (rho). The level of statistical significance was $\mathrm{p}<0.05$ (2-tailed).

\section{Results}

Sixty RA patients were included in the present study. They were 52 (86.7\%) females and 8 (13.3\%) males. Their ages ranged from 22-75 years with a mean of $49.1 \pm 13$ years, disease duration ranged from 1-30 years with a mean of $8.9 \pm 6.9$ years. 30 age and sex matched healthy control were also enrolled. They were $24(80 \%)$ females and 6 (20\%) males.

Their ages ranged from $23-72$ years with a mean of $42.3 \pm 11.8$ years. Five patients were smokers $(8.3 \%), 14(23.3 \%)$ were performing regular oral hygiene, $24(40 \%)$ had secondary Sjögren's syndrome, TMJ was affected in $34(56.7 \%)$, CDAI was $26.1 \pm 17.3$, MHAQ was $1.04 \pm 0.68$. RF was positive in $50(83.3 \%)$ patients, ACPA was positive in 52 $(86.7 \%)$ patients with a mean titer of $185.9 \pm 126.3 \mu / \mathrm{ml} .38(63.3 \%)$ patients were receiving methotrexate (MTX), 32 (53.3\%) leflunomide, and 33 (55\%) were on low dose steroid ( $\leq 7.5 \mathrm{mg})$.

The frequency of periodontitis in patients was $43(71.7 \%)$ versus 14 $(46.7 \%)$ in control $(\mathrm{p}=0.02)$. Table 1 compares between patients and control demographic data, PD frequency, severity and indices.

There was a significant difference as regards PD degree $(\mathrm{p}=0.01)$ with predominance of moderate and severe degree in RA patients. Generalized form $(\mathrm{p}=0.004)$, PI $(\mathrm{p}<0.0001)$, GI $(\mathrm{p}=0.001)$, PPD $(\mathrm{p}=0.01)$ and CAL index $(\mathrm{p}<0.0001)$ were highly significant in RA 
Citation: Fathi HM, Khairy N, Gheita TA, El Battawy WA, Taha R (2018) Clinical Significance of Periodontitis in Rheumatoid Arthritis Patients:

Page 3 of 7

patients. Teeth loss was evident in RA patient than control with up to 32 teeth loss $(\mathrm{p}<0.0001)$.

\begin{tabular}{|c|c|c|c|}
\hline $\begin{array}{l}\text { Variable } \\
\text { Mean } \pm \text { SD (range)l } \\
\text { n(\%) }\end{array}$ & $\begin{array}{l}\text { RA patients } \\
(n=60)\end{array}$ & $\begin{array}{l}\text { Control } \\
(n=30)\end{array}$ & $\mathbf{p}$ \\
\hline Age (years) & $49.1 \pm 139(22-75)$ & $42.3 \pm 11.8(23-72)$ & 0.3 \\
\hline Female & $52(86.7)$ & $24(80)$ & \\
\hline male & $8(13.3)$ & $6(20)$ & 0.4 \\
\hline Smoking & $5(8.3)$ & $4(13.3)$ & 0.4 \\
\hline Regular oral hygiene & $14(23.3)$ & $6(20)$ & 0.7 \\
\hline PD positivity & $43(71.7)$ & $14(46.7)$ & 0.02 \\
\hline \multicolumn{4}{|l|}{ PD degree: } \\
\hline Zero & $17(28.3)$ & $15(50)$ & \\
\hline Mild & $10(16.7)$ & $7(23.3)$ & 0.01 \\
\hline Moderate & 19(31.3) & $8(26.7)$ & \\
\hline severe & $14(23.3)$ & $0(0)$ & \\
\hline \multicolumn{4}{|l|}{ Localized PD: } \\
\hline Yes & $10(16.7)$ & $7(23.3)$ & 0.4 \\
\hline No & $50(83.3)$ & $23(76.6)$ & \\
\hline \multicolumn{4}{|l|}{ Generalized PD: } \\
\hline Yes & $33(55)$ & $7(23.3)$ & \\
\hline No & $27(45)$ & $23(76.6)$ & 0.004 \\
\hline \multicolumn{4}{|l|}{ Plaque index(PI): } \\
\hline Grade 0 & $15(25)$ & $15(50)$ & \\
\hline Grade 1 & $2(3.3)$ & $8(26.7)$ & 0.0001 \\
\hline Grade 2 & $17(28.3)$ & $7(23.3)$ & \\
\hline Grade 3 & $26(43.3)$ & $0(0)$ & \\
\hline \multicolumn{4}{|l|}{ Gingival index: } \\
\hline 0 & $15(25)$ & $15(50)$ & \\
\hline 1 & $11(18.3)$ & $11(36.7)$ & \\
\hline 2 & $20(33.3)$ & $4(13.3)$ & 0.001 \\
\hline 3 & $14(23.3)$ & $0(0)$ & \\
\hline Teeth loss : & & & $<0.0001$ \\
\hline Yes & $51(85)$ & $9(30)$ & \\
\hline No & $9(15)$ & $21(70)$ & \\
\hline Teeth loss number & $8.5 \pm 11.2(0-32)$ & $0.4 \pm 0.8(0-3)$ & $<0.0001$ \\
\hline PPD & $2.05 \pm 1.2(0-4)$ & $1.4 \pm 0.7(0.5-3.5)$ & 0.01 \\
\hline CAL & $\begin{array}{l}1.96 \\
(0-4.7)\end{array} \pm 1.68$ & $0.6 \pm 0.8(0-3.1)$ & $<0.0001$ \\
\hline
\end{tabular}

SD: standard deviation, PD: periodontitis, RA: rheumatoid arthritis,
PPD: probing pocket depth, CAL: clinical attachment loss

Table 1: Demographic features, periodontitis frequency, severity and indices in rheumatoid arthritis patients and control.

A comparison between RA patients with PD (RA-PD) vs. without is shown in Table 2. There was a significant difference in age $(\mathrm{p}=0.007)$ and disease duration $(\mathrm{p}<0.0001)$ but not with gender, smoking or oral hygiene. Also, MS ( $\mathrm{p}=0.01)$, CDAI $(\mathrm{p}<0.0001)$, MHAQ $(\mathrm{p}=0.02)$ and CRP ( $\mathrm{p}=0.02)$ were significantly higher in RA-PD patients. Neither RF nor anti-CCP positivity was different, however, anti-CCP titer was significantly higher in RA-PD $(\mathrm{p}=0.01)$. Radiographic scoring was insignificantly different $(\mathrm{p}=0.3)$. As regard the medication received, only MTX was significant $(\mathrm{p}=0.005)$. None of the present patients was receiving a biologic therapy.

\begin{tabular}{|c|c|c|c|}
\hline \multirow{2}{*}{$\begin{array}{l}\text { Variable } \\
\text { Mean } \pm \text { SD (range)/n(\%) }\end{array}$} & \multicolumn{2}{|c|}{ RA patients $(n=60)$} & \multirow{3}{*}{$\begin{array}{l}p \\
0.007\end{array}$} \\
\hline & $\begin{array}{l}\text { RA-PD } \\
(n=43)\end{array}$ & $\begin{array}{l}\text { RA only } \\
(n=17)\end{array}$ & \\
\hline Age & $46.3 \pm 12.3$ & $56.18 \pm 12.3$ & \\
\hline Female & $35(81.4)$ & $17(100)$ & 0.056 \\
\hline Male & $8(18.6)$ & $0(0)$ & \\
\hline Disease duration (years) & $6.36 \pm 5.2$ & $15.5 \pm 6.3$ & $<0.0001$ \\
\hline smoking & $3(7)$ & $2(11.8)$ & 0.5 \\
\hline Oral hygiene & $10(23.3)$ & $4(23.5)$ & 0.9 \\
\hline \multicolumn{4}{|l|}{ MS } \\
\hline$\leq 60 \mathrm{~min}$ & $31(72.1)$ & $17(100)$ & 0.01 \\
\hline$>60 \mathrm{~min}$ & $12(27.9)$ & $0(0)$ & \\
\hline SC nodules & $14(32.6)$ & $5(29.4)$ & 0.8 \\
\hline Secondary Sjögren's & $24(40)$ & $8(47.1)$ & 0.4 \\
\hline TMJ & $24(55.8)$ & $10(58.8)$ & 0.8 \\
\hline CDAI & $31.56 \pm 17.49$ & $12.47 \pm 4.99$ & $<0.0001$ \\
\hline MHAQ & $1.17 \pm 0.68$ & $0.69 \pm 0.58$ & 0.02 \\
\hline $\mathrm{ESR}(\mathrm{mm} / 1 \mathrm{sthr})$ & $52.36 \pm 27.18$ & $39.9 \pm 16$ & 0.2 \\
\hline CRP positivity & $24(55.8)$ & $4(23.5)$ & 0.02 \\
\hline RF positivity & $34(79.1)$ & $16(94.1)$ & 0.1 \\
\hline Anti-CCP positivity & $38(88.4)$ & $14(82.4)$ & 0.5 \\
\hline Anti-CCPTiter(U/mL) & $213.7 \pm 131.57$ & $115.59 \pm 78.06$ & 0.01 \\
\hline \multicolumn{4}{|l|}{ Radiographic score: } \\
\hline Grade 1 & $10(23.3)$ & $4(23.5)$ & \\
\hline Grade 2 & $12(27.9)$ & $4(23.5)$ & 0.3 \\
\hline Grade 3 & $15(34.9)$ & $9(34.9)$ & \\
\hline Grade 4 & $6(14)$ & $0(0)$ & \\
\hline Medications: & & & \\
\hline
\end{tabular}


Citation: Fathi HM, Khairy N, Gheita TA, El Battawy WA, Taha R (2018) Clinical Significance of Periodontitis in Rheumatoid Arthritis Patients: Association with Disease Activity and Functional Status. J Arthritis 7: 268. doi:10.4172/2167-7921.1000268

Page 4 of 7

\begin{tabular}{|l|l|l|l|}
\hline MTX & $32(74.4)$ & $6(35.3)$ & 0.005 \\
\hline Leflunomide & $26(60.5)$ & $6(35.3)$ & 0.07 \\
\hline Steroid low dose & $23(53.5)$ & $10(58.8)$ & 0.7 \\
\hline HCQ & $16(37.2)$ & $9(52.9)$ & 0.2 \\
\hline
\end{tabular}

SD: standard deviation, RA-PD: rheumatoid arthritis having periodontitis,

MS:morning stiffness, SC nodules: subcutaneous, TMJ: tempromandibular

joint, CDAI:clinical disease activity index, MHAQ: modified health assessment

questionnaire, ESR: erythrocyte sedimentation rate, CRP: $C$ reactive protein,

RF: rheumatoid factor,Anti CCP: anti cyclic citrullinated peptide,

MTX: methotexate, $\mathrm{HCQ}$ :hydroxychloroquine, n: number

Table 2: Demographic features, clinical, laboratory, radiographic score and medications in rheumatoid arthritis patients with and without periodontitis.

Table3 demonstrates a comparison between early and late RA regarding PD. PD was higher in early 26 (96.3\%) vs. late RA 17 (51.5\%) patients $(\mathrm{p}<0.0001)$. In early RA, moderate $(40.7 \%)$ and severe PD degree (37\%) were present versus $24.2 \%$ and $12.1 \%$ respectively in late RA ( $\mathrm{p}=0.001)$. Generalized PD was more frequent $(92.6 \%)$ in early vs $24.2 \%$ in late RA, the PI ( $\mathrm{p}=0.002)$, GI $(\mathrm{p}=0.001), \operatorname{PPD}(\mathrm{p}=0.01)$ and CAL $(p<0.0001)$ indices were significantly higher in early cases. However teeth loss was higher in late RA (93.9\%) vs. early $(74.1 \%)$ $(\mathrm{p}=0.03)$. The mean number of lost teeth in late was $13.8 \pm 12.8(0-32)$ vs. $1.9 \pm 1.8(0-6)$ in early patients. Difference was insignificant between early vs. late RA in CDAI ( $p=0.2)$ or MHAQ ( $p=0.4)$.

\begin{tabular}{|c|c|c|c|}
\hline \multirow{2}{*}{$\begin{array}{l}\text { Variable } \\
\text { Mean } \pm \text { SD }(\text { range }) / \mathrm{n}(\%)\end{array}$} & \multicolumn{2}{|c|}{ RA patients $(n=60)$} & \multirow{3}{*}{$\begin{array}{l}\mathrm{p} \\
<0.0001\end{array}$} \\
\hline & $\begin{array}{l}\text { Early RA-PD } \\
(n=26)\end{array}$ & $\begin{array}{l}\text { Late RA-PD } \\
(n=33)\end{array}$ & \\
\hline PD & $26(96.3)$ & $17(51.5)$ & \\
\hline \multicolumn{4}{|l|}{ PD degree: } \\
\hline Zero & $1(3.7)$ & $16(48.5)$ & \\
\hline Mild & $5(18.5)$ & $5(15.2)$ & 0.001 \\
\hline Moderate & $11(40.7)$ & $8(24.2)$ & \\
\hline severe & $10(37)$ & $4(12.1)$ & \\
\hline Localized PD & $1(3.7)$ & $9(27.3)$ & $<0.0001$ \\
\hline Generalized PD & $25(92.6)$ & $8(24.2)$ & \\
\hline \multicolumn{4}{|l|}{$\mathrm{PI}:$} \\
\hline Grade 0 & $1(3.7)$ & $14(42.4)$ & \\
\hline Grade 1 & $0(0)$ & $2(6.1)$ & \\
\hline Grade 2 & $10(37)$ & 7 (21.1) & 0.002 \\
\hline Grade 3 & $16(59.3)$ & $10(30.3)$ & \\
\hline \multicolumn{4}{|l|}{$\mathrm{Gl}:$} \\
\hline Grade zero & $1(3.7)$ & $14(42.4)$ & \\
\hline
\end{tabular}

\begin{tabular}{|l|l|l|l|}
\hline Grade 1 & $4(14.8)$ & $7(21.1)$ & \\
\hline Grade 2 & $15(55.6)$ & $5(15.2)$ & 0.001 \\
\hline Grade 3 & $7(25.9)$ & $7(21.2)$ & \\
\hline Teeth loss: & & & \\
\hline Yes & $20(74.1 \%)$ & $31(93.0 \%)$ & 0.03 \\
\hline No & $7(25.9 \%)$ & $2(6.1 \%)$ & \\
\hline Number of lost teeth & $1.9 \pm 1.8(0-6)$ & $13.8 \pm 12.8(0-32)$ & $<0.0001$ \\
\hline PPD & $2.6 \pm 0.7(0.9-4)$ & $1.5 \pm 1.4(0-4)$ & 0.01 \\
\hline CAL & $2.9 \pm 1.4(0-4.7)$ & $1.1 \pm 1.3(0-4.3)$ & $<0.0001$ \\
\hline
\end{tabular}

SD: standard deviation, RA-PD: rheumatoid arthritis having periodontitis, $\mathrm{PI}$ : plaque index, GI: gingival index, PPD: probing pocket depth, CAL: clinical attachment loss, n: number

Table 3: Comparison between early and late RA regarding the presence of periodontitis and different scores.

Correlations between PD indices with disease activity scores, morning stiffness, ESR, anti-CCP titer and radiographic score are presented in Table 4 . There was a significant correlation between MHAQ and all PD indices. CDAI, VAS and anti-CCP titer all significantly correlated with all PD indices except number of teeth loss.

MS correlated with all PD indices except GI and number of teeth loss. ESR correlated with all PD indices except PI and GI. Radiographic score only correlated with the number of teeth loss $(r=0.4, p=0.001)$.

\begin{tabular}{|c|c|c|c|c|c|c|}
\hline \multirow{2}{*}{$\begin{array}{l}\text { Variable } \\
r(p)\end{array}$} & \multicolumn{6}{|c|}{$\begin{array}{l}\text { Periodontitis degree and indices in rheumatoid arthritis } \\
\text { patients }(n=60)\end{array}$} \\
\hline & PD degree & $\mathbf{P I}$ & GI & PPD & CAL & $\begin{array}{l}\text { Number of } \\
\text { lost teeth }\end{array}$ \\
\hline \multirow[t]{2}{*}{ MS(minutes) } & 0.002 & 0.04 & 0.06 & 0.01 & 0.002 & 0.14 \\
\hline & 0.3 & 0.2 & 0.2 & 0.3 & 0.3 & 0.19 \\
\hline \multirow[t]{2}{*}{ CDAI } & 0 & 0 & 0 & 0 & 0 & 0.7 \\
\hline & 0.7 & 0.5 & 0.5 & 0.6 & 0.7 & 0.03 \\
\hline \multirow[t]{2}{*}{ MHAQ } & 0 & 0.004 & 0.003 & 0.004 & 0.001 & 0.004 \\
\hline & 0.5 & 0.3 & 0.3 & 0.3 & 0.4 & 0.3 \\
\hline \multirow[t]{2}{*}{$\mathrm{ESR}(\mathrm{mm} / 1 \mathrm{sthr})$} & 0.002 & 0.2 & 0.4 & 0.02 & 0.001 & 0.03 \\
\hline & 0.3 & 0.1 & 0.1 & 0.2 & 0.4 & 0.2 \\
\hline \multirow[t]{2}{*}{ VAS } & 0 & 0 & 0 & 0 & 0 & 0.8 \\
\hline & 0.6 & 0.4 & 0.4 & 0.5 & 0.5 & -0.02 \\
\hline \multirow{2}{*}{$\begin{array}{l}\text { Anti-CCP } \\
\text { titer(U-ml) }\end{array}$} & 0 & 0.002 & 0.003 & 0 & 0 & 0.06 \\
\hline & 0.6 & 0.3 & 0.3 & 0.4 & 0.6 & 0.2 \\
\hline \multirow{2}{*}{$\begin{array}{l}\text { Radiographic } \\
\text { Score }\end{array}$} & 0.6 & 0.09 & 0.8 & 0.7 & 0.5 & 0.001 \\
\hline & 0.06 & 0.4 & 0.02 & 0.04 & 0.07 & 0.4 \\
\hline
\end{tabular}

PD: Periodontitis, PI: Plaque Index, GI: Gingival Index, PPD: Probing Pocket Depth, CAL: Clinical Attachment Loss, MS: Morning Stiffness, CDAl: Clinical Disease Activity Index, MHAQ: Modified Health Assessment Questionnaire, 
ESR: Erythrocyte Sedimentation Rate, VAS: Visual Analogue Scale, Anti CCP: Anti Cyclic Citrullinated Peptide, n: number.

Table 4: Correlations between different periodontitis indices and disease activity, morning stiffness erythrocyte sedimentation rate, anticyclic citrullinated peptide and radiographic score in rheumatoid arthritis patients.

\section{Discussion}

$\mathrm{RA}$ is an autoimmune disease characterized by progressive inflammation and involvement of T-cells, B-cells and proinflammatory cytokines [26,27]. It is characterized by progressive disability, systemic complications and early death [28]. Observably, there was mutual relation between RA and PD not only on the scale of frequency [2] but also on etio-pathological event [7], pathobiologic processes [8], genetic risk factors [9] and histopathological level [11]. The aim of this work was to determine frequency of periodontitis in Egyptian RA patients and to find a possible association of periodontal indices and/or severity with disease activity, functional status, antiCCP and RF serology and radiographic score.

In the present work, the frequency of PD in control was $46.7 \%$, among which mild PD was represented in $23.3 \%$ and moderate in 26.7\%. This was in agreement with the National Health and Nutrition Examination Survey (NHANES) in 2009-2010 that demonstrated the overall rate of PD in the general population over age of 30 was $47.2 \%$, with moderate PD in 30\% and severe PD in $8.5 \%$ [29].

In the current study the frequency of PD was significantly higher in RA patients; $96.3 \%$ in early RA and $24 \%$ in late RA. PD degree was predominantly moderate and severe in RA patients versus the control $(\mathrm{p}=0.01)$. Generalized form of PD was more dominant in RA patients $(\mathrm{p}=0.004)$, and all indices which reflect $P D$ severity. This was in agreement with a study which examined anti- $P$. gingivalis $(\mathrm{Pg})$ to evaluate the oral microbiome in groups of individuals with early and established RA, compared with healthy adults [30]. The higher frequency of $\mathrm{PD}$ in RA patients could be attributed to proinflammatory properties of $\mathrm{Pg}$ which may serve as a triggering factor in various mucosal sites, particularly in genetically predisposed individuals [31]. Furthermore, another study recorded PD in $80 \%$ of patients with early RA and in $85 \%$ of patients with chronic RA vs. $40 \%$ of controls documenting the poorer periodontal health in RA patients [32]. This documentation could be explained by weakened immune defense in the host due to RA and increased systemic inflammation which may initiate or enhance the severity of periodontitis $[33,34]$.

In the current work CRP positivity was significantly higher in RA$\mathrm{PD}$ vs. RA patients, $(\mathrm{p}=0.02)$. These periodontal lesions were suggested to be the origin for daily bacteraemia and even raise systemic inflammation reflected in markers as CRP [35]. A recent study showed that patients with chronic RA with severe periodontitis had higher CRP values compared with corresponding early RA participants [32]. Further assessment of the degree of periodontitis in CRP positive RA patients demonstrated; no PD in $14 \%$, mild PD in $7 \%$, moderate PD $36 \%$, and severe PD in $43 \%$ with a highly significant value $(\mathrm{p}=0.002)$. Perhaps there would be better judgment if quantitative CRP was done.

Longitudinal studies on PD patients on long term periodontal maintenance programs have reported that a small subgroup of patients appear to be particularly susceptible to disease, with periodontitis progression occurring despite ongoing maintenance care [36]. In the current work, the local risk factors such as PD was not associated with neglected oral hygiene, TMJ involvement which was in agreement with another study and also, with secondary Sjogren as well [37]. The importance of the host response in determining susceptibility to chronic periodontitis was clearly documented in carefully conducted longitudinal observational studies of tea plantation workers in Sri Lanka. These individuals had no access to dental care, did not routinely use conventional oral hygiene products, and presented with generalized plaque and calculus deposits. Yet, within this population, around $11 \%$ were considered to be stable, with no evidence of progression of periodontitis, another group (81\%) demonstrated moderate progression of periodontitis, and $8 \%$ showed rapid disease progression [38]. Intensity of gingival inflammation varies widely between individuals following plaque accumulation, suggesting that susceptibility to disease varies between individuals due to differences in the inflammatory host response, rather than being entirely due to differences in the amount and/or composition of the bacterial plaque [39].

In the current work, PD severity indices were correlated with RA activity scores. These finding was in agreement with Äyräväinen and others, 2017 where PD indices correlated with different RA activity scores. These findings reflect the parallel authentic - pathologic process between RA and PD.

Also, smoking was not different in RA patients perhaps, due to presence of pathway for citrullination process in RA independent to smoking, although being one of important extrinsic risk factors in RA with a patho-physiological process including oxidative stress, autoantibody Production, inflammation and epigenetic changes [40].

In the present work, radiographic scoring was not significantly different among the two groups (PD-RA vs RA), while radiographic scoring was correlated with number of teeth loss this was in agreement with Marrotte and colleagues, 2006 where alveolar bone loss in PD-RA patients parallels RA erosions at other sites [11]. It could be explained by similar process in PD and RA where inflammation is at the heart of destructive process. In PD inflammation is intended to defend the host against the bacterial challenge, but prolonged and/or excessive inflammation results in tissue damage and progressive breakdown of periodontal ligament fibres ("loss of attachment") resulting in increased probing depths, and resorption of alveolar bone, and the tissue damage that occurs is largely irreversible [22]. Also in RA the main triggers of articular bone erosion are synovitis, including the production of pro-inflammatory cytokines and receptor activator of nuclear factor $\mathrm{\kappa B}$ ligand (RANKL), as well as antibodies directed against citrullinated proteins, both cytokines and autoantibodies stimulate the differentiation of bone-resorping osteoclasts, thereby stimulating local bone resorption [41].

On evaluating the effect of anti-rheumatic medications on periodontal parameters, low doses corticosteroids were insignificant. This was in agreement with studies that showed, no difference in periodontal parameters with corticosteroids use [30,33]. While, another study reported an association between the use of corticosteroids and higher levels of CAL and deepened periodontal pocket depth and demonstrated significant effect of methotrexate (MTX) on periodontal parameters [42]. The current study found that MTX was significantly related. Similarly, an increased frequency of MTX-induced oral mucosal ulcers was demonstrated [43]. On the other hand, it has been reported that MTX and loflunamide had no effect on dental status [20,42,44]. Furthermore, Äyräväinen et al 2017, reported that biologic therapy do not worsen periodontitis in RA 
patients. In fact, there was a trend for improvement in pocket depths [32].

\section{Main Conclusion}

There is a mutual relation between the disease activity and functional status in RA with the frequency and severity of PD, being the first and most recent Egyptian study done in rheumatoid arthritis patients'. Dental assessment and attention to oral hygiene assume an increasingly important part of the clinical management of the RA patients. Furthermore, closer attention to oral health in all patients will improve quality of life and address what is now recognized as an important RA co-morbidity. Routine periodontal examination is recommended for all RA patients. Also, a higher number of patients may be recommended in future studies and to be conducted on a larger scale.

\section{Conflict of Interest}

None

\section{Funding}

No funding or financial support

\section{References}

1. Lee JY, Choi IA, Kim JH, Kim KH, Lee EY, et al. (2015) Association between anti- Prophyromonus gingivalis or anti- $\alpha$ enolase antibody and severity of periodontitis or rheumatoid arthritis (RA) disease activity in RA. BMC musculoskeletal Disorder 16: 190.

2. Cochran DL (2003) Inflammation and bone loss in periodontal disease. J Periodontol 79: 1569-1576.

3. Sidebottom A, Salha R (2013) Management of the temporomandibular joint in rheumatoid disorders. Br J Oral Maxillofac Surg 51: 191-198.

4. Abroa AL, Santana CM, Bezerra AC, de Amorim RF, da Silva MB, et al. (2016) What rheumatologists should know about orofacial manifestations of autoimmune rheumatic diseases. Rev Bras Reumatol Engl Ed 56: 441-450.

5. Sokolove J, Bromberg R, Deane K, Lahey L, Derber L, et al. (2012) Autoantibody epitope spreading in the preclinical phase predicts progression to rheumatoid arthritis. Plos One 7: e35296.

6. McGraw WT, Potempa J, Farley D, Travis J (1999) Purification, characterization and sequence analysis of a potential virulence factor from Porphyromonas gingivalis, peptidylarginine deiminase. Infect Immun 67: 3248-3256.

7. Bartold P, Marino V, Cantley M, Haynes DR (2010) Effect of P. gingivalis induced inflammation and the developmentof rheumatoid arthritis. J Clin Periodontol 37: 405-411.

8. Culshaw S, McInnes I, Liew F (2011) What can the periodontal community learn from pathophysiology of RA? J Clin Periodontol 38: 106-113.

9. Bonfil J, Dillier F, Mercier P, Reviron D, Foti B, et al. (1999) A case control study on the role of HLA-DR4 in severe and rapidly progressive periodontitis: identification of types and subtypes using molecular biology. J Clin Periodontol 26: 77-84.

10. Ishida K, Kabayshi T, Itos S, Komatsu Y, Yokoyama T, et al. (2012) IL-6 gene promotor methylation in RA and chronic periodontitis. J Periodontol 83: 917-925.

11. Marotte H, Farge P, Gaudin P, Alexandre C, Mougin B, et al. (2006) The association between periodontitis and joint destruction in RA extends the link between HLA-DR shared epitope and severity of bone destruction. Ann Rheum Dis 65: 905-909.
12. Kaneko C, Kobayashi T, Ito S, Sugita N, Murasawa A, et al. (2018) Circulating levels of carbamylated protein and neutrophil extracellular traps are associated with periodontitis severity in patients with rheumatoid arthritis: A pilot case-control study. PLoS One 13: e0192365.

13. Verheul MK, Vierboom MPM, Hart BA, Toes REM, Trouw LA (2017) Anti-carbamylated protein antibodies precede diseases onset in monkeys with collagen-induced arthritis. Arthritis Res Ther 19: 246.

14. Bright R, Thiele GM, Manavis J, Mikuls TR, Payne JB, et al. (2018) Gingival tissue, an extra-synovial source of malondialdehydeacetaldehyde adducts, citrullinated and carbamylated proteins. J periodontal Res 53: 139-143.

15. Levin R, Park J, Ostrov B, Reginato A, Baker DG, et al. (1996) Clinical assessment of the 1987 American College of Rheumatology criteria for rheumatoid arthritis. Scand J Rheumatol 25: 277-281.

16. Aletaha D, Smolen J (2005) The Simplified Disease Activity Index (SDAI) and the Clinical Disease Activity Index (CDAI): A review of their usefulness and validity in rheumatoid arthritis. Clin Exp Rheumatol 23: 100-108.

17. Pincus T, Yazici Y, Bergman M (2005) Development of a multidimensional health assessment questionnaire (MD-HAQ) for the infrastructure of standard clinical care. Clin Exp Rheumatol 23: 19-28.

18. Scott D, Houssien D, Lassonen L (1995) Proposed modifications to Larsen's scoring method for hand and wrist radiographs. Br J Rheumatol 34: 156.

19. Armitage GC (2002) Classifying periodontal diseases-a longstanding dilemma. Periodontol 30: 9-23.

20. Van der Velden U (2000) Diagnosis of periodontitis. J Clin Periodontol 27: 960-961.

21. Lopez R, Baelum V (2003) Classifying periodontitis among adolescents: implications for epidemiological research. Community Dent Oral Epidemiol 3: 136-143.

22. Silness J, Löe H (1964) Periodontal Disease in Pregnancy. II. Correlation between oral hygiene and periodontal condition. Acta Odontol Scand 22: 121-135.

23. Löe H (1967) The gingival index, the plaque index and the retention index systems. J Periodontol 38: 610-616.

24. Zimmermann H, Hagenfeld D, Diercke K, El-Sayed N, Fricke J, et al. (2015) Pocket depth and bleeding on probing and their associations with dental, lifestyle, socioeconomic and blood variables: a cross-sectional, multicenter feasibility study of the German National Cohort. BMC Oral Health 15: 7 .

25. Kinane D, StathopolouP, Papapanou P (2008) Once periodontal clinical attachment and/or bone loss are evident, the goal of treatment is to control inflammation. Lancet 371: 237-242.

26. Chapple IL (2009) Periodontal diagnosis and treatment - where does the future lie? Periodontol 51: 9-24.

27. Choy E (2012) Understanding of dynamics: pathways involved in the pathogenesis of rheumatoid arthritis. Rheumatology oxford 51: v3-v11.

28. Mc Innes IB, Schett G (2011) The pathogenesis of rheumatoid arthritis. N Engl J Med 365: 2205-2219.

29. Eke PI, Dye BA, Wei L, Thornton-Evans GO, Genco RJ, et al. (2012) Prevalence of periodontitis in adults in United Sates: 2009-2010. J Dent Res 91: 914-920.

30. Scher JU, Ubeda C, Equinda M, Khanin R, Buischi Y, et al. (2012) Periodontal disease and theoral microbiota in new-onset rheumatoid arthritis. Arthritis Rheum 64: 3083-3094.

31. Samuel B, Steven B, Jose U (2014) Microbiome and mucosal inflammation as an extra - articular triggers for rheumatoid arthritis and autoimmunity. Curr Opin Rheumatol 26: 101-107.

32. Äyräväinen L, Leirisalo-Repo M, Kuuliala A, Ahola K, Koivuniemi R, et al. (2017) Periodontitis in early and chronic rheumatoid arthritis: a prospective follow up study in Finnish population. BMJ Open 7: e011916.

33. Wolff B, Berger T, Frese C, Max R, Blank N, et al. (2014) Oral status in patients with early rheumatoid arthritis: a prospective, case-control study. Rheumatology (Oxford) 53: 526-531. 
Citation: Fathi HM, Khairy N, Gheita TA, El Battawy WA, Taha R (2018) Clinical Significance of Periodontitis in Rheumatoid Arthritis Patients: Association with Disease Activity and Functional Status. J Arthritis 7: 268. doi:10.4172/2167-7921.1000268

Page 7 of 7

34. Payne JB, Golub LM, Thiele GM, Mikulus TR (2015) The link between periodontitis and rheumatoid arthritis: a periodontist's perspective. Curr Oral Health Rep 2: 20-29.

35. Loos BG (2005) Systemic markers of inflammation in periodontitis. J Periodontol 76: 2106-2115.

36. McFall WT Jr (1982) Tooth loss in 100 treated patients with periodontal disease. A long-term study. J Periodontol 53: 539-549.

37. Lange L, Thiele GM, McCracken C, Wang G, Ponder L, et al. (2016) Symptoms of periodontitis and antibody responses to Porphyromonas gingivalis in juvenile idiopathic arthritis. Pediatr Rheumatol Online J 14: 8.

38. Loe H, Anerud A, Boysen H, Morrison E (1986) Natural history of periodontal disease in man. Rapid, moderate and no loss of attachment in Sri Lankan labourers 14 to 46 years of age. J Clin Periodontol 13: 431-445.

39. Trombelli L, Tatakis DN, Scapoli C, Bottega S, Orlandini E, et al. (2004) Modulation of clinical expression of plaque-induced gingivitis. II.
Identification of "high-responder" and "low-responder" subjects. J Clin Periodontol 31: 239-252.

40. Chang K, Yang SM, Kim SH, Han KH, Park SJ, et al. (2014) Smoking and rheumatoid arthritis. Int J Mol Sci 15: 22279-22295.

41. Schett G, Gravallese E (2012) Bone erosion in rheumatoid arthritis: mechanisms, diagnosis and treatment. Nat Rev Rheumatol 8: 656-664.

42. Beeraka SS, Natarajan K, Patil R, Manne RK, Prathi VS, et al. (2013) Clinical and radiological assessment of effects of long-term corticosteroids therapy on oral health. Dent Res J (Isfahan) 10: 666-673.

43. Mays J, Sarmadi M, Moutsopoulos N (2012) Oral manifestations of systemic autoimmune and inflammatory diseases: diagnoses and clinical management. J Evid Based Dent Pract 12: 265-282.

44. Han JY, Reynolds MA (2012) Effect of anti-rheumatic agents on periodontal parameters and biomarkers of inflammation: a systematic review and meta-analysis. J Periodontal Implant Sci 42: 3-12. 